\title{
GRADIENT ANALYSIS OF VEGETATION ON THE SOUTH SLOPE OF VITOSHA MOUNTAIN, SOUTHWEST BULGARIA
}

\author{
DYAKOV, NIKOLAY R. \\ Dendrology Department, University of Forestry, \\ 10 Kliment Ohridski Blvd. 1756, Sofia, Bulgaria \\ e-mail:nickydyakov@gmail.com
}

(Received $10^{\text {th }}$ March 2014; accepted $22^{\text {nd }}$ July 2014)

\begin{abstract}
Detailed analysis of the relationship between vegetation and environment requires a thorough understanding of the environmental processes that influence vegetation. There is an intimate relationship between vegetation concepts' development, mathematical methods of analysis and knowledge of environmental processes. Traditionally most vegetation/environment studies have been done at a single scale of observation. It has been considered important to assess whether the processes that determine community structure and function are similar at different scales or whether the most important processes change with the scale of observation. This study aims to describe in a quantitative manner the vegetation pattern in a localized area and on that basis to test/verify statistically some previously proposed hypothesis and assumption concerning vegetation organization. Describing the coarsest vegetation pattern, ordination and classification analyses were used. The detailed relationships between environmental gradients and vegetation were examined using regression and correlation methods. Obtained results were tested with different statistical tests for their reliability. We found that the basic environmental gradients influencing the local vegetation are elevation and habitat moisture. The correlation between environmental gradients and vegetation increased with the increasing scale of observation. Environmental gradients influencing vegetation most strongly were the same at the different scales. With the increase of sampled area, correlation strength between environment and vegetation also increased. In the future, if possible, all studies of vegetation/environment relationships should be done at different spatial scales. Gathered quantitative information and verified hypothesis in the current study could be very successfully used in the management and conservation of the local and regional vegetation.

Keywords: vegetation variables, ordination, correlation, regression, CCA, GAM
\end{abstract}

\section{Introduction}

Detailed analysis of the relationship between vegetation and environment requires a thorough understanding of the environmental processes that influence vegetation (Austin 2005). There is an intimate relationship between vegetation concepts' development, mathematical methods of analysis and knowledge of environmental processes. Austin (2005) postulated tree fundamental questions which can account for these aspects: 1) Is vegetation pattern continuous or discontinuous and how is this pattern related to environment? 2) What theory and methods are most appropriate for investigating such patterns? 3) What is the relative importance of environment and factors intrinsic to the vegetation in determining the observed patterns?

Answering these questions requires appropriate methods for vegetation/environment analysis. Until now numerous such methods have been developed. For example, direct ordination or direct gradient analysis, is the analysis of species distributions (presence/absence or abundance data) and collective properties (e.g. species richness) in relation to environmental variables conventionally referred to as environmental gradients (Austin 2005). On the contrary, the indirect ordination or indirect gradient analysis, determines the major gradients of variation to be found in the vegetation data itself. A graphical representation of the variation in vegetation across all sites can be 
constructed by measuring the similarity between each site based on the species composition. Such an ordination diagram summarizes the major axes of variation in the vegetation data matrix (Austin 2005).

Studying the vegetation of Santa Catalina Mountains and using gradient analysis approach, Whittaker and Niering (1975) found some tendencies, concerning important vegetation variables, that can be observed and that can possibly imply the answers of the previous three questions: 1) within the tree layer, no correlation between the species richness and productivity was evident; 2) among perennial herbs both diversity and productivity showed bimodal distribution and weak correlation between them; 3) weak correlation of diversity and productivity was observed, when all shrub life forms were grouped together; 4) for the dominants' strata, there were no correlation between diversity and productivity in habitats where these layers were dominant; and 5) in temperate vegetation the tree layer was in general poorer on species than shrub and herb strata; herb and shrub layers were on average less rich under closed forest canopies than in open communities. The current study tried to verify all these hypothesis.

Traditionally most vegetation/environment studies have been done at a single scale of observation (Reed at al. 1993). It has been considered important to assess whether the processes that determine community structure and function are similar at different scales or whether the most important processes change with the scale of observation (Reed at al. 1993). Studying the understory vegetation of North Carolina at different spatial scales, Reed et al. (1993) proposed few hypothesis which we also try to test: 1) the correlation between vegetation composition and environment increases with increasing quadrat size; 2) the environmental factors most highly correlated with species composition and richness should be similar at all scales and should be among the environmental factors strongly correlated with species composition over the much larger extent; 3) with increased extent of sampling the correlation between environment and vegetation should also increase.

Structure, composition and post-disturbance forest development could be studied in the context of local environmental gradients. Investigations of most community and ecosystem properties including diversity, biomass and productivity need to be conducted within a multidimensional framework including both site condition and stand development. Similarly, studies of population change during succession need to be placed in an environmental context (Peet 1981). Resulting from his study, Peet (1981) proposed tree models of stand development, depending of the local site conditions: 1) favorable middle-elevation sites; 2) highest or middle elevation sites in very dry conditions; 3) lower elevation sites with episodic regeneration and favorable conditions. The current study tried to analyze the local stands, aiming to place them in the context of these tree models.

Explicit testing of vegetation patterns according to environmental gradients has yet to be achieved. Descriptive vegetation patterns resulting from gradient analyses combined with statistical modelling can be of exceptional benefit. Understanding these patterns is an essential ingredient in sustainable vegetation management, despite that there are still many questions to be answered in vegetation science (Austin 2005). 


\section{Material and Methods}

\section{Study area}

Vitosha Mountain is located in Western Bulgaria. It is characterized with compactness and well expressed elevation gradient. The mountain has steep slopes and variable expositions. Its vegetation has variable species composition. The current study embraced the south slope of the mountain. GPS coordinates of that territory are between $\mathrm{N} 42^{\circ} 32^{\prime}$ E23 ${ }^{\circ} 09^{\prime}$ and $\mathrm{N} 42^{\circ} 26^{\prime} \mathrm{E} 23^{\circ} 21^{\prime}$. The area covers $118 \mathrm{~km}^{2}$. For details about the studied area, refer to Dyakov $(2012,2013)$.

\section{Sampling}

Sampling strategy was based on gradsect method of Austin \& Heyligers (1991). Its advantages are: 1) relatively cheap, 2) highly effective, 3 ) easy to apply on the field, but requiring experienced workers. During the summers of 2008 and 2009, a total of 159 $(0.1 \mathrm{ha})$ samples were taken. Detailed information on the field techniques can be found in previous papers (Dyakov 2012; Dyakov 2013; Dyakov \& Zhelev 2013).

\section{Environmental gradients}

Four indirect or factor-complex (sensu Whittaker 1978) environmental gradients were used - elevation, exposition, slope inclination and slope convexity. According to Austin \& Smith (1989) and Austin (2005), indirect gradients influence direct gradients such as temperature and rainfall which have direct effect on plant growth. On a local scale, the author recommends measuring and using indirect gradients because they have much more meaningful influence on vegetation. For detailed information on gradient quantification methodology, refer to Dyakov (2012).

\section{Scale}

Traditionally, vegetation structure and correlation of vegetation and environment have been analyzed at a single scale of observation, using one quadrate size. However, different ecological processes are important at different spatial and temporal scales and dependent on the scale of observation (Reed et al. 1993). We analyzed vegetation patterns at two different spatial scales using two data sets. First data set was composed of 1590.1 ha field plots. Second one comprises $8431 \mathrm{~m}^{2}$ field subplots.

\section{Ordination and Classification}

Using divisive classification algorithm of Two-Way INdicator SPecies ANalysis (TWINSPAN) (Hill 1979), all samples were clustered into compositional groups or community types. The cluster analysis was run with checked default program options. This method not only classifies the samples, but also constructs double-ordered table from the data matrix (samples $\times$ species). Combination of these characteristics made it one of the most popular programs in vegetation ecology nowadays.

The general picture of the vegetation pattern in the environmental space was outlined with direct gradient analysis, using Canonical Correspondence Analysis (CCA) (ter Braak 1986). Being a method for direct gradient analysis, CCA explains the variation in the data on the basis of preliminary chosen environmental gradients (Jongman et al. 2004). The main advantages of CCA are: 1) the simultaneous ordering of sites and species (if needed), 2) rapid computation, 3) very good performance when species have

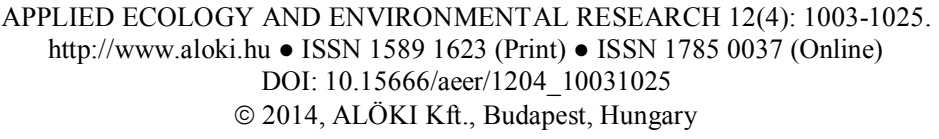


nonlinear and unimodal relationships to environmental gradients, and 4) robustness to violation of preliminary assumptions (Palmer 1993).

Trying to clarify the relationship between the environmental gradients and vegetation species composition we also used indirect gradient analysis - Detrended Correspondence Analysis (DCA). DCA constructs theoretical variables which best explain data variance without the necessity of preliminary introduced environmental variables. This is done by choosing most adequate sample scores, i.e. these ones which maximize the explained variance in species composition. When the result are plotted on the biplot, the two axes (first and second) are these theoretical variables which explain greatest percentage of data variance, being uncorrelated each other (Jongman et al. 2004). Two different DCA ordinations were carried out with two data sets at the two different spatial scales of observation.

\section{Correlation and Regression}

Trying to reveal the detailed relationships between the species distribution or abundance and the environmental gradients, we used multiple regression and correlation techniques. Because correlated variables were not normally distributed we used nonparametric correlation coefficient of Spearman, $R_{S}$ (Spearman 1904).

The aim of regression analysis is to describe the dependent variable as a function of one or multiple independent ones. Using regression analyses, dependent variables can be predicted (described) with minimal or less statistical error (Jongman et al. 2004). General Additive Models (GAM) were used as a multiple regression method. The aim of GAM models is to maximize the quality of the dependent variable description, which may have various distributions. GAM does so by developing unspecified nonparametric functions of the independent variables, which are "connected" with the depended variable by link function (Thomas \& Mitchell 1991).

\section{Statistical tests}

Obtained results were tested for significance with Monte Carlo Permutation test and $F$-test. In all statistical tests, the significance level was $P<0.05$ unless shown otherwise.

In all analyses the following specialized software products were used: STATISTICA, version 8.0 (StatSoft 2007); CANOCO for Windows, version 4.51 (ter Braak \& Smilauer 2003); CanoDraw for Windows, version 4.1 (Smilauer 2003).

\section{Results}

\section{General picture of local vegetation pattern}

TWINSPAN classification resulted in 14 clusters, shown with different symbols in Figure 1 (for the full names of plant communities see the Legend below the Figure 1), which represents the summarized picture of the studied vegetation, set in the context of the four preliminary chosen environmental gradients. The latter are considered as the most important local environmental gradients, playing fundamental role in vegetation organization on the south slope of Vitosha Mountain.

For the correct interpretation of CCA biplot, it should be noticed, that the longer the arrow of the corresponding environmental variable, the more highly correlated it is to the ordination axis in its close proximity. Moreover, the closer the sample (symbol) point of given plant community is to the arrow point (or to that part of the biplot, to 


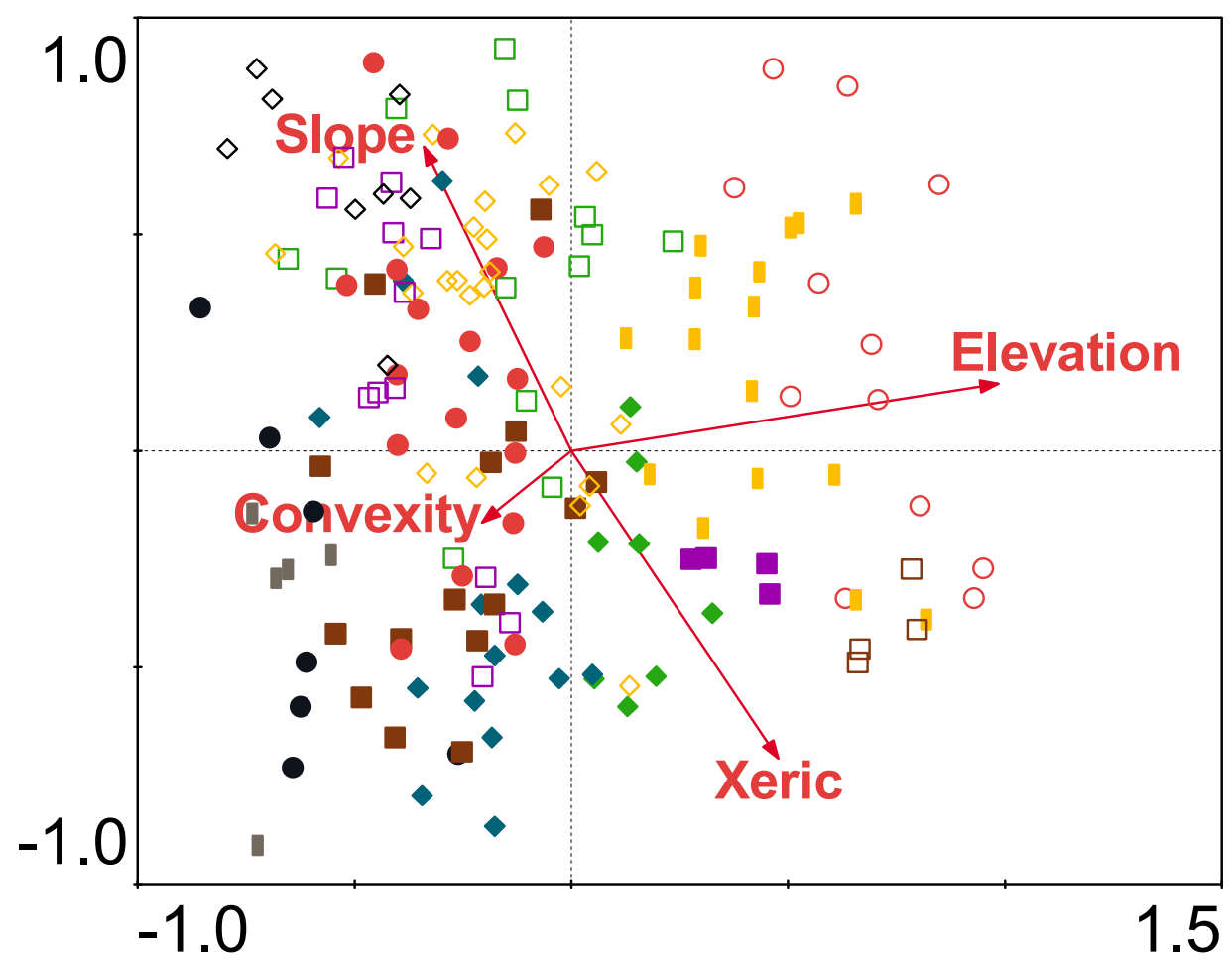

\section{Legend:}

Fagus sylvatica-Hepatica nobilis $(n=8)$

Fagus sylvatica-Physospermum cornubiense $(n=12)$

Fagus sylvatica-Galium odoratum ( $n=13)$

Fagus sylvatica-Luzula luzuloides $(n=23)$

Fagus sylvatica-Festuca drymeja $(n=17)$

Fagus sylvatica-Corylus avellana-Brachypodium pinnatum $(n=15)$

Pinus sylvestris-Fragaria vesca $(n=15)$

Pinus nigra-Crataegus monogyna $(n=5)$

Quercus cerris-Cornus mas ( $n=6$ )

Festuca pseudodalmatica-Chamaespartium sagittale $(n=4)$

Galium verum-Thymus glabrescens $(n=8)$

Juniperus sibirica-Vaccinium myrtillus $(n=16)$

Juniperus sibirica-Vaccinium myrtillus-Vaccinium vitis-idaea $(n=12)$

Juniperus sibirica-Sesleria comosa $(n=4)$

Figure 1. Ordination of the 159 samples $(0.1 \mathrm{ha})$ in the context of local indirect environmental gradients. Community types are denoted with the Latin names of dominant plant species composing them. Elevation = altitude above sea level; Xeric = moisture gradient; Slope $=$ slope inclination in degrees; Convexity = slope convexity (for details on the indirect gradient methodology see cited papers in Material and Methods section). 
which the arrow is pointed out) the greater is the importance of the corresponding environmental gradient for the vegetation in these habitats.

Statistical parameters of the CCA analysis (Table 1) show that first axis alone as well as all axes taken together at the two scales are highly statistically significant $(P=0.002)$.

Table 1. Statistical parameters of CCA ordination

\begin{tabular}{cccccc}
\hline \multicolumn{5}{c}{ 0.1 ha scale $(\boldsymbol{n}=\mathbf{1 5 9})$} \\
\hline CCA axes & 1 & 2 & 3 & 4 & Total inertia \\
\hline Eigenvalues: & 0.651 & 0.253 & 0.120 & 0.067 & 9.706 \\
\hline Monte Carlo test of the CCA axes (499 permutations) \\
\hline \multicolumn{5}{c}{$F=11.067$} & $P=0.002$ \\
First canonical axis & $F=4.875$ & $P=0.002$ \\
\hline & All axes & $\mathbf{1 ~ m}^{2}$ scale $(\boldsymbol{n}=\mathbf{8 4 3})$ \\
\hline CCA axes & 1 & 2 & 3 & 4 & Total inertia \\
\hline Eigenvalues: & 0.676 & 0.315 & 0.263 & 0.097 & 52.863 \\
\hline Monte Carlo test of the CCA axes (499 permutations) \\
\hline First canonical axis & $F=10.859$ & $P=0.002$ \\
All axes & $F=5.497$ & $P=0.002$ \\
\hline
\end{tabular}

CCA ordination of the dominant species, composing local vegetation, i.e. these species, most highly correlated with the local environmental gradients, is represented on Figure 2. These plant species also have greatest importance for the formation of studied vegetation.

The open subalpine vegetation is located at the right part of the biplot, found only at relatively higher elevation (Figure 1). The more mesophytic plant communities (such as Juniperus sibirica-Vaccinium myrtillus-Vaccinium vitis-idaea and Juniperus sibiricaVaccinium myrtillus) are positioned at the upper right part, while the subalpine shrub and herb plant communities, preferring more xeric, sunny slopes and ridges (Juniperus sibirica-Sesleria comosa, Festuca pseudodalmatica-Chamaespartium sagittale and Galium verum-Thymus glabrescens) are localized in the right lower biplot part. Similar positions have the plant species dominant in the corresponding vegetation. In the upper right part of Figure 2 are found more mesophytic herb species like Hypericum maculatum, Sesleria comosa, Vaccinium myrtillus, Vaccinium vitis-idaea, Rubus idaeus, Calamagrostis arundinacea etc., while the lower right part is occupied by plant species preferring more xeric and poor habitats, like Festuca nigrescens, Agrostis capillaris, Achillea millefolium, Thymus glabrescens, Chamaespartium sagittale, Trifolium alpestre, Galium verum etc.

Forest vegetation and the species composing it are located at the left part of the CCA biplots (Figure 1 and Figure 2). Forest vegetation on the south slope of Vitosha most often reaches its limit around $1600 \mathrm{~m}$ a.s.l. Forest communities exceed this altitudinal limit only at some isolated places. For example, it happens along some deep moist ravines with permanent or seasonal upland streams. Lower left part of Figure 1 is occupied by subxeric and xeric forests, developed at lower elevation (including some pine plantations, still surviving after being planted there in the past). These are plant communities such as Pinus nigra-Crataegus monogyna, Pinus sylvestris-Fragaria vesca, Quercus cerris-Cornus mas and Fagus sylvatica-Corylus avellanaBrachypodium pinnatum. They are preferred by species like Quercus cerris, Pinus sylvestris, Crataegus monogyna, Rosa canina, Corylus avellana, Brachypodium pinnatum, Fragaria vesca and others (Figure 2). At the upper left part of the biplot 
(Figure 1) are found more mesic forest communities, dominated completely by the common beech, occupying steeper mountainous slopes. These are Fagus sylvaticaHepatica nobilis, Fagus sylvatica-Physospermum cornubiense, Fagus sylvatica-Galium odoratum, Fagus sylvatica-Luzula luzuloides and Fagus sylvatica-Festuca drymeja communities. These communities are dominated also by plant species like Mycelis muralis, Lamium galeobdolon, Hepatica nobilis, Viola riviniana, Aremonia agrimonoides, Helleborus odorus etc.

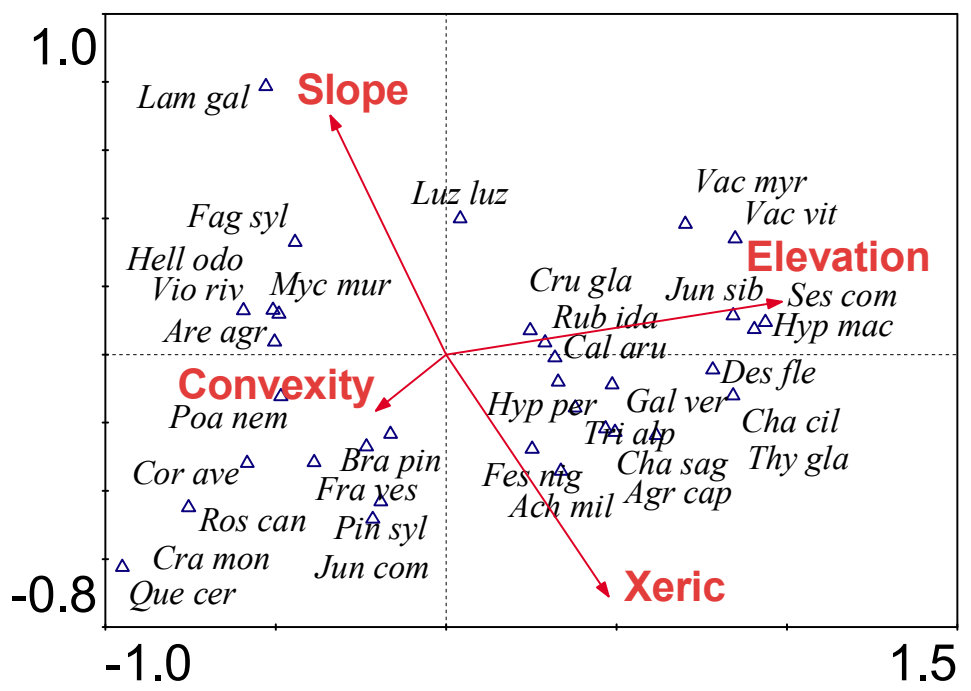

Figure 2. Ordination of dominant plant species in the context of local indirect environmental gradients. Plant species are denoted with the first three or four letters of their genus and species name as follows: Lam gal = Lamium galeobdolon (L.) Ehrend. \& Polatschek; Fag syl = Fagus sylvatica L.; Hell odo = Helleborus odorus Waldst. \& Kit. ex Willd. ; Vio riv = Viola riviniana Rchb.; Myc mur = Mycelis muralis Dumort.; Are agr = Aremonia agrimonoides (L.) DC.; Poa $n e m=$ Poa nemoralis $L$.; Co rave $=$ Corylus avellana L.; Bra pin = Brachypodium pinnatum

(L.) P. Beauv.; Fra ves $=$ Fragaria vesca $L$.; Ros can $=$ Rosa canina $L$.; Pin syl $=$ Pinus sylvestris L.; Cra mon = Crataegus monogyna Jacq.; Jun com = Juniperus communis L.; Que cer $=$ Quercus cerris L.; Cal aru = Calamagrostis arundinacea (L.) Roth; Des fle $=$ Deschampsia flexuosa (L.) Trin.; Cal ver $=$ Galium verum L.; Hyp per $=$ Hypericum perforatum L.; Tri alp = Trifolium alpestre L.; Cha cil = Chamaecytisus ciliatus (Wahlenb.) Rothm.; Thy gla = Thymus glabrescens Wild.; Cha sag = Chamaespartium sagittale (L.) Gibbs; Fes nig = Festuca nigrescens Lam.; Agr cap = Agrostis capillaris L.; Ach mil = Achillea millefolium L.;

Luz luz = Luzula luzuloides (Lam.) Dandy; Vac myr = Vaccinium myrtillus L.; Vac vit $=$ Vaccinium vitis-idaea L.; Cru gla $=$ Cruciata glabra (L.) Ehrend.; Jun sib = Juniperus sibirica Burgsd.; Ses com = Sesleria comosa Velen.; Hyp mac = Hypericum maculatum Crantz; Rub ida = Rubus idaeus L.

\section{Correlation between the environmental gradients and vegetation}

\section{Gradient relationships}

Correlation between some vegetation variables and the four DCA axes (surrogate of the underlying environmental gradients) at the two scales of measurement, are represented in Table 2. Table 3 shows the correlations between the environmental gradients and vegetation variables themselves. 
It is obvious that the elevation is most highly positively correlated with the first DCA axes at the two scales. First DCA axis correlates highly positively with moisture gradient too, as well as highly negatively related with the slope inclination. Second DCA axis is most highly positively correlated to moisture gradient and negatively to the slope inclination at 0.1 ha scale. At the $1 \mathrm{~m}^{2}$ scale it correlates strongly negatively with the elevation. First DCA axis is considered to be latent expression of elevation gradient and the second DCA axis - the change of microhabitat conditions, governed by the change of slope inclination, slope exposition and topography. It is hard to interpret third and fourth DCA axes despite the significant correlations found. One probable reason for this is the small number of environmental gradients used or their indirect (complex) influence on the vegetation. Anyway, elevation and moisture gradients explain the greatest part of data variation; therefore we consider them as variables with profound influence on vegetation composition and structure.

\section{Vegetation cover}

Strong negative correlation is found between tree layer cover and the first two DCA axes at the two scales of observation. This holds also for the correlation with elevation and moisture gradient (Table 3). It is considered as a proof for the correct interpretation of CCA biplot. The negative correlation in the second case can be explained with the more xeric habitat conditions at the slope ridges, where forests, if at all present, have more open character (these are most often pine plantations). Strong positive correlation is found between the slope inclination and tree layer cover. Steep slope bases in the close proximity to temporal or permanent springs are occupied predominantly by beech forests which are characterized with highly closed canopies.

We have found strong positive correlation between herb cover and first DCA axis at the two scales of measurement. This is true for the elevation gradient too. At the higher altitudes, due to lack of forest vegetation, the herb layer reaches its highest cover, approaching at some places $100 \%$.

Shrub cover does not show clear tendency, except that it correlates highly positively with phanerophyte number. Herb cover correlates strongly positively with the elevation and xeric gradients and negatively with the slope inclination. In the second case, it is due to the more abundant herb layer, developed under the more open canopy of the xeric pine plantations and mixed oak forests, giving the opportunity to greater number of shrub and herb species to survive. These forests are distributed in drier habitats on more sloping places. On the other hand, beech forests, with some exceptions, are almost completely spared of shrub and herb layers. Shrub cover correlates significantly only with the elevation and it is negative relationship (Table 3).

\section{Plant life forms}

Strong positive correlation has been found between first DCA axis and the chamaephytes, hemicryptophytes and therophytes (Table 3) at the two scales of measurement. Strong positive correlation is also observed between the chamaephytes and the elevation as well as between the hemicryptophytes, elevation and xeric habitats. Cryptophytes correlate negatively with the two main environmental gradients elevation and xeric habitats. Therophytes somehow repeat the tendency of chamaephytes and hemicryptophytes. 
Table 2. Correlation (nonparametric correlation coefficient of Spearman, $R_{s}$ ) between DCA axes, indirect environmental gradients and vegetation variables. Correlation coefficients greater than 0.4 are shown with Bold type; $n s=$ not significant; $* P<0.05 ; * * P<0.01$; $* * * P<0.001$.

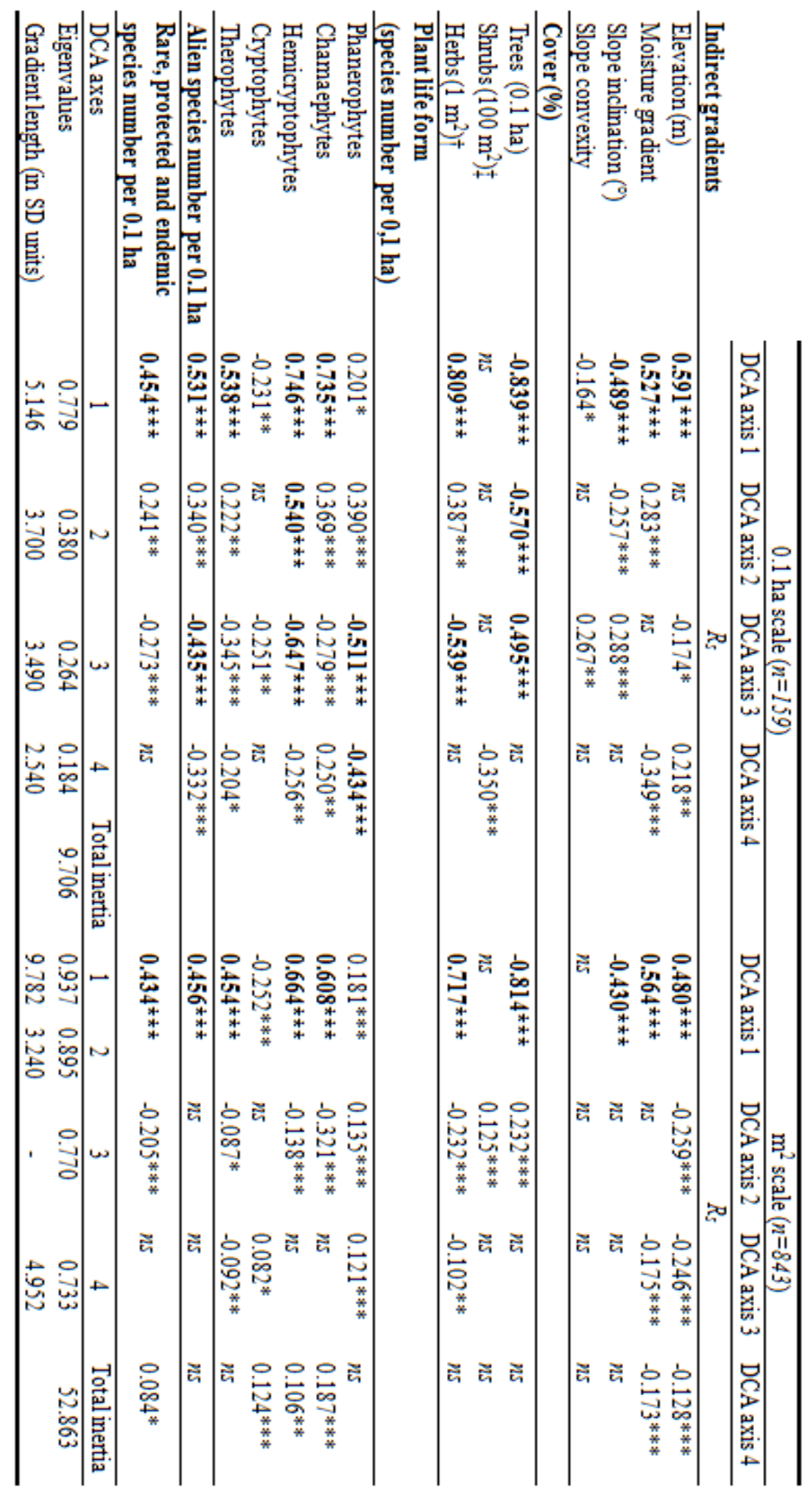

Note: $\neq$ means shrub cover per $100 \mathrm{~m}^{2} ;+$ mean herb cover per $1 \mathrm{~m}^{2}$. 
Table 3. Correlation (nonparametric correlation coefficient of Spearman, $R_{s}$ ) between indirect environmental gradients and vegetation variables. Correlation coefficients greater than 0.4 are shown with Bold type; $n s=$ not significant; ${ }^{*} P<0.05 ;{ }^{* *} P<0.01 ;{ }^{* *} P<0.001$.

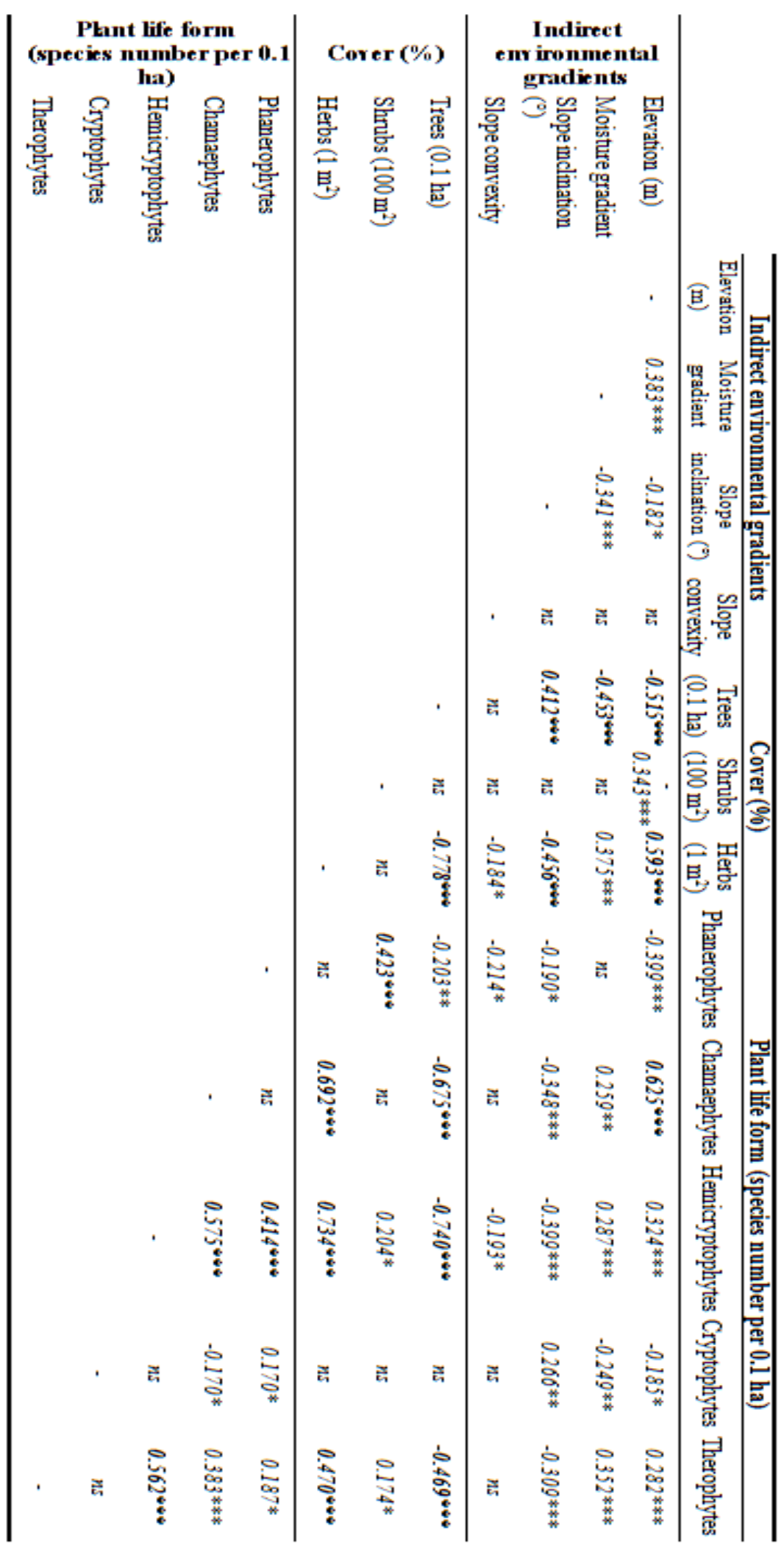


These results can be explained with the greater number of life forms in the open subalpine communities compared to the forest ones. With the exception of cryptophytes, all other life forms correlate negatively with the slope inclination and the greater part of them do not correlate significantly with the slope topography.

The positive correlation between first DCA axis and most life forms at the two measurement scales can be explained with the more open pattern of the xerophilic forests where greater numbers of species from most life forms are present. They are also more saturated with ruderals which most often belong to the therophyte life form. Richer on species (mainly chamaephytes and hemicryptophytes) are the open subalpine pastures, distributed above the tree line.

Significant positive correlations have been found between the cover of vegetation layers and most life forms (Table 3). For example, chamaephytes, therophytes and hemicryptophytes show similar relationship with the vegetation cover. These life forms correlate negatively with closed canopy forests and positively with the open grassy communities which, most often, have high herb coverage. On the other hand, phanerophyte number correlates positively with the shrub layer cover and negatively with the canopy closure. This is explained with the greater share of shrubs in that life form and the greater number of phanerophytes occupying the more open mixed oak forests and pine plantations. Cryptophytes do not show any significant correlation with vegetation layers. The correlation analysis of life forms themselves shows that hemicryptophytes correlate positively with the phanerophytes and chamaephytes as well as hemicryptophytes with therophytes.

\section{Alien and rare plant species}

Strong positive correlation between the number of alien species and first DCA axis have been found at the two measurement scales, implying that the xeric habitats, located at low and high elevation, are more prone to alien species invasion (Table 2). Concerning the open subalpine communities, this is probably connected to the high species richness as a whole, whereas the more xerophilic forests, being distributed at lower altitude, closer to human settlement, are more highly affected by the negative anthropogenic activities like logging, fires, grazing of livestock, etc.

The open subalpine pastures are occupied by greater number of rare, protected and endemic species per unit area (Table 2). This is confirmed by the high positive correlation between the first DCA axis and the number of rare plant species.

\section{Scale}

The number and power of the correlations between the DCA axes and the environmental variables increases with the scale extension (Table 2). This is most clearly demonstrated for the second and higher DCA axes. Explained variation is much greater at the coarsest scale which is probably due to the greater sample number at the finer scale and the greater data heterogeneity at that level. However, obtained results confirm the first tested hypothesis that the correlation between vegetation composition and environmental gradients increases with the increasing size of the sampling plots.

It is also obvious that the correlations between the first tree environmental gradients and the DCA axes are statistically significant at the two levels of measurement which is 
confirmation of the second tested hypothesis that environmental gradients correlated most strongly with the vegetation composition should be similar at the different scales.

The correlation between the environmental gradients is stronger at that scale which covers greater area of the studied territory (Table 2). This is the database with the 0.1 ha sampling plots which covers totally 15.9 ha, versus the smaller scale database, covering only $834 \mathrm{~m}^{2}$. This unambiguously supports the third tested hypothesis that with the increasing area covered by the sampling plots, the correlation between environment and vegetation should also increase.

\section{Regression}

Cover

The detailed picture of the relationship between vegetation and local indirect environmental gradients on the south slope of Vitosha Mountain is revealed with the multiple regression analysis. Response surfaces of the vegetation layer cover as a function of main environmental gradients are represented on Figure 3. The four environmental gradients are denoted with arrows and shortened names (for the full names, see Figure 1). Isolines represent the predicted layer cover (\%) in the abstract ecological space, designed by the used regression model. Statistical parameters of the models are shown in Table 4.
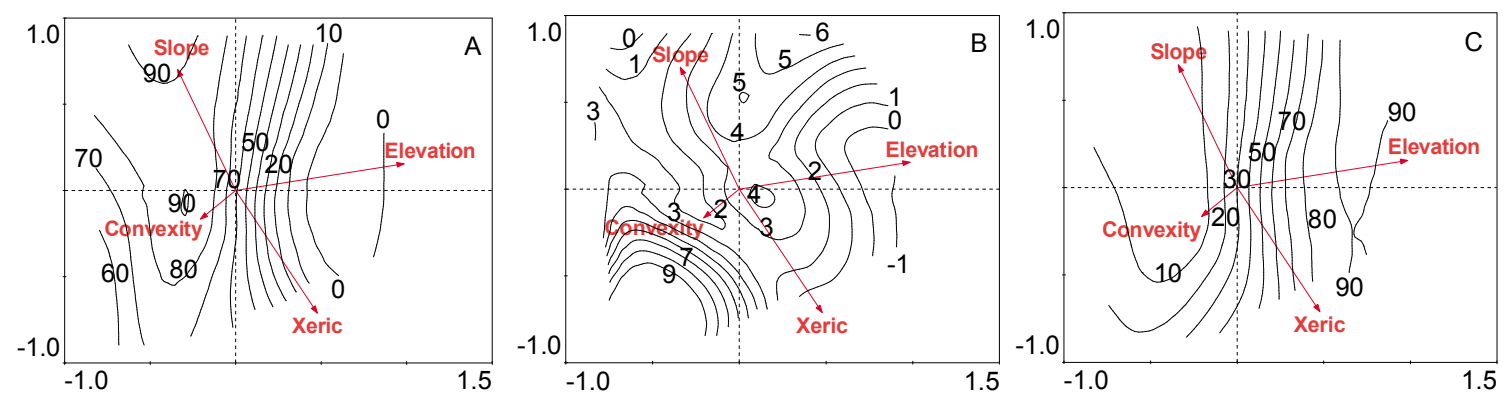

Figure 3. Regression response surfaces of vegetation layer cover (\%) in the context of local indirect environmental gradients. Isolines show predicted cover of: $A=$ tree layer; $B=$ shrub layer; $C=$ herb layer.

Table 4. Statistical parameters of the regression models. ${ }^{*} P<0.05 ; * * * P<0.001$;

\begin{tabular}{lccc}
\hline Variable & Distribution & Model & Model significance $(\boldsymbol{F})$ \\
\hline Mean tree cover per $0.1 \mathrm{ha}$ & Gaussian & GAM & $120.55^{* * *}$ \\
Mean shrub cover per $100 \mathrm{~m}^{2}$ & Gaussian & GAM & $3.77^{*}$ \\
Mean herb cover per $1 \mathrm{~m}^{2}$ & Gaussian & GAM & $105.37^{* * *}$ \\
\hline
\end{tabular}

Maximal tree layer cover is predicted for the beech zone, located between 1200-1400 $\mathrm{m}$, which becomes wider towards the more mesic habitats at the same elevation (Figure 3). The ecological surface of that variable has Gaussian distribution (Table 4). Other forests with high canopy closure occupy the most xeric habitats at about $1300 \mathrm{~m}$. The former case concerns the beech forests from the deep moist ravines at the slope bases 
where the forest canopy closure exceeds $85-90 \%$. The other forests with very high tree layer cover are the coppice beech communities found on flat or convex slopes in the most xeric habitats, where they form very dense sprouting stem pattern and highest canopy closure, reaching over $95 \%$ cover. In the xeric habitats, localized at lower altitudes (1200-1000 m), mixed oak forest canopies as well as pine plantation canopies do not reach over $80 \%$ cover and continue to fall with the decreasing elevation. On the other hand, with the increase of elevation above $1300 \mathrm{~m}$, tree canopy closure starts to decrease, but this is happening faster in the more xeric places. Above 1500-1600 m on the south slope of Vitosha Mountain, forest vegetation gives way to the subalpine pastures.

Shrub cover correlates negatively with the elevation gradient (Table 3). However, there is no clear tendency in the relationship with the moisture gradient. From Figure 3, it is evident that shrub cover shows complex response surface, but the statistical test of its form confirmed it to be Gaussian (Table 4).

The maximal shrub cover is predicted for the submesic places at about $1200 \mathrm{~m}$ as well as for the mesic habitats in the 1400-1600 m elevation belt. The former case is connected with the mixed oak forests and pine plantations at lower altitude, whereas the later one concerns the Pinus sylvestris plantations at middle elevation. In the beech forests, shrub cover reaches its minimum.

Herb cover correlates positively with the elevation and habitat moisture, but negatively with the slope inclination. It reaches its maximum in the mesic subalpine habitats, distributed above $1800 \mathrm{~m}$ elevation. Herb cover in the forest belt reaches its lowest scores in the beech communities, but increases in the more xeric habitats at middle and lower elevation, where pine plantations and mixed oak forests dominate.

\section{Plant life forms}

Plant life form distribution in the context of the local environmental gradients is represented on Figure 4. The isolines depict the predicted species number by life form per 0.1 ha. Table 5 shows the statistical significance of used models as well as the distribution of ecological surfaces and plant life form spectrum. Phanerophytes reach their maximum in the xeric and subxeric habitats at about or below $1000 \mathrm{~m}$ (Figure 4A). The beech forests and plant communities above the tree line have the lowest number of phanerophytes. With the elevation increase, phanerophyte number decreases much faster in the mesic habitats than in the xeric ones. Chamaephytes show the opposite trend (Figure 4B). They have highest species richness in the submesophilic and mesophilic open subalpine communities (mainly species from Ericaceae) and with the elevation decrease, their richness also decreases. Below $1500 \mathrm{~m}$ elevation, they are almost lacking.

Hemicryptophytes have complex (bimodal) distribution. The first mode is located in the most xeric habitats of the subalpine belt at elevations between 1800-2000 $\mathrm{m}$. The second one is centered in the xeric places at elevation around and less than $1000 \mathrm{~m}$, where mixed oak forests and mixed pine plantations dominate. A third, slighter mode, appears in the most mesic habitats at about 1800-2000 m. Hemicryptophytes show highly abrupt decrease with the approaching of mesic and submesic beech forests, developed at about 1300-1400 m elevation (Figure 4C). With the ascending above 2000 $\mathrm{m}$ their number also falls. Cryptophytes have their mode located in the mesophytic beech forests distributed on steeper slopes along moist ravines at about $1200 \mathrm{~m}$ (Figure 
$4 D$ ). With the ascending towards higher elevation (above 1700-1800), in the most xeric habitats, they disappear. Therophytes have similar distribution to chamaephytes, showing bimodal response surface. The first mode appears at about 1600-1700 $\mathrm{m}$ in the most xeric subalpine places, and the second one is located at about and lower than 1000 $\mathrm{m}$ elevation, in the subxeric habitats (Figure 4E). Their number is lowest in the mesophilic and submesophilic beech forests, distributed at about 1200-1300 m elevation.
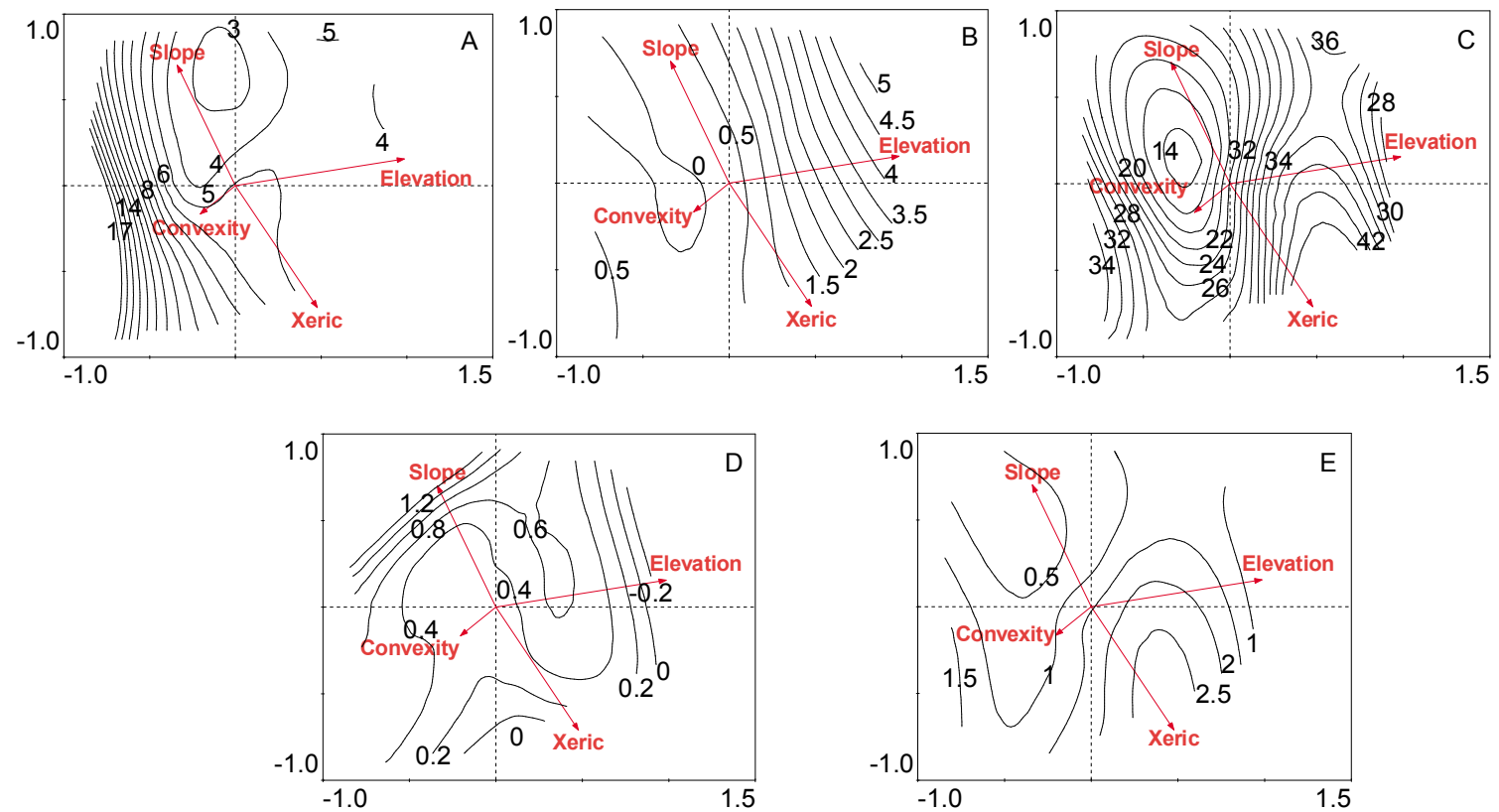

Figure 4. Regression response surfaces of the plant life forms in the context of local indirect environmental gradients. Isolines show predicted species number per 0.1 ha by plant life form as follows: $A$ = Phanerophytes; $B=$ Chamaephytes; $C=$ Hemicryptophytes; $D=$ Cryptophytes; $E=$ Therophytes.

Table 5. Statistical parameters of the regression models. ${ }^{*} * * P<0.001$.

\begin{tabular}{|c|c|c|c|c|}
\hline Variable & Distribution & Model & Model significance & Plant life form spectrum \\
\hline $\begin{array}{l}\text { Phanerophyte } \\
\text { species number per } \\
0.1 \text { ha }\end{array}$ & Complex & GAM & $29.54 * * *$ & 14.14 \\
\hline $\begin{array}{l}\text { Chamaephyte } \\
\text { species number per } \\
0.1 \text { ha }\end{array}$ & Gaussian & GAM & $61.44 * * *$ & 1.39 \\
\hline $\begin{array}{l}\text { Hemicryptophyte } \\
\text { species number per } \\
0.1 \text { ha }\end{array}$ & Complex & GAM & $17.13^{* * *}$ & 72.31 \\
\hline $\begin{array}{l}\text { Cryptophyte species } \\
\text { number per } 0.1 \text { ha }\end{array}$ & Gaussian & GAM & $10.99 * * *$ & 3.18 \\
\hline $\begin{array}{l}\text { Therophyte } \\
\text { species number per } \\
0.1 \text { ha }\end{array}$ & Gaussian & GAM & $10.41 * * *$ & 8.96 \\
\hline
\end{tabular}




\section{Stand structure}

Regression surfaces of stem distribution by diameter classes in the ecological space are represented on Figure 5. Table 6 can be referred for the model significance and regression surface distributions.
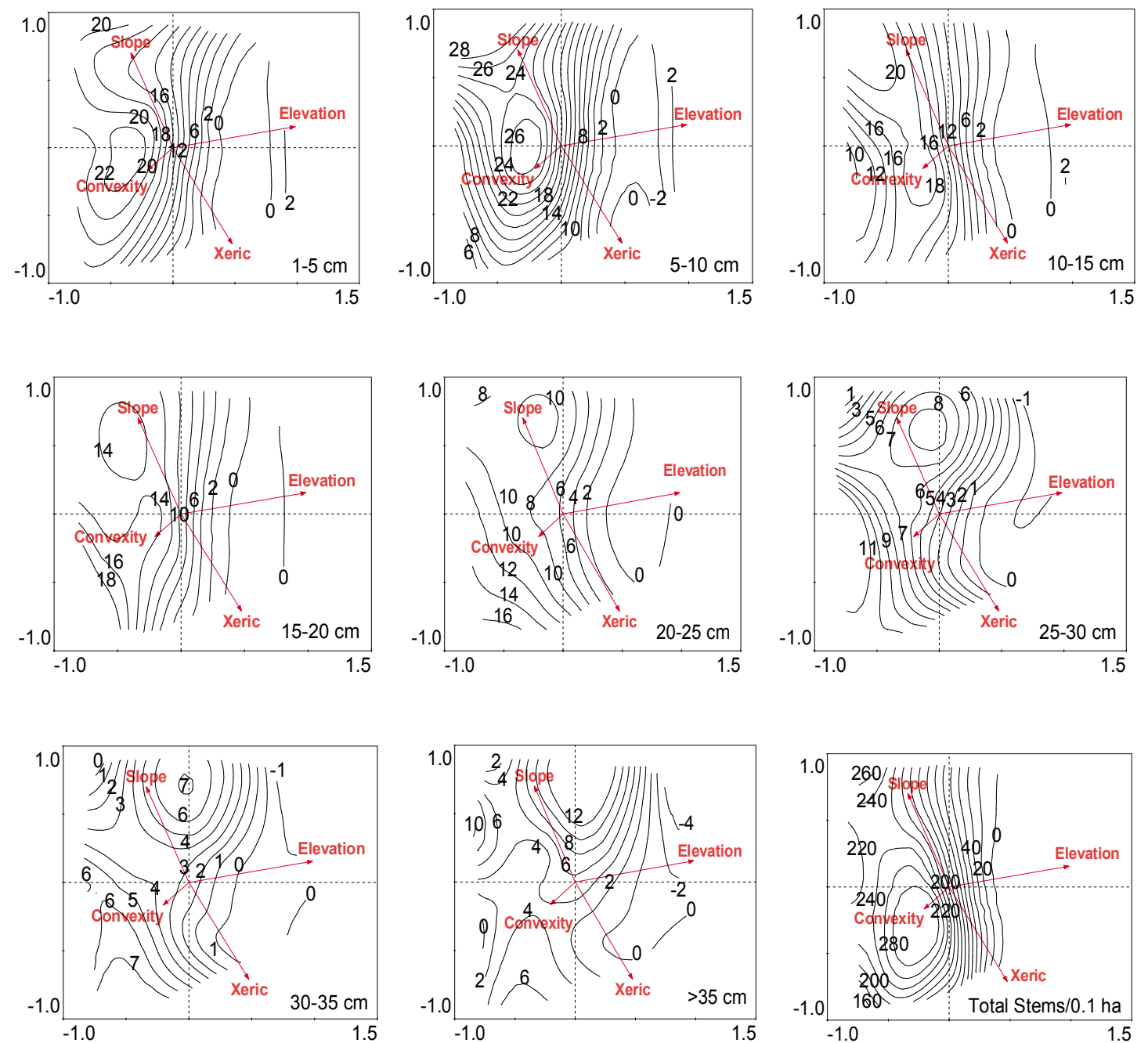

Figure 5. Regression response surfaces of tree and shrub stem diameter (greater than $1 \mathrm{~cm}$ at breast height $\approx 130 \mathrm{~cm}$ ) in the context of local indirect environmental gradients. Isolines show predicted stem percentage in the stand per $0.1 \mathrm{ha}$. Stem diameter classes are show in the lower right corner of the graphs. Lower right-corner graph shows total stem number per $0.1 \mathrm{ha}$.

All diameter classes have asymmetric or complex distribution. The greatest stem number from 1-5 cm diameter class can be found in the submesic and subxeric habitats at about $1200 \mathrm{~m}$, but also below $1000 \mathrm{~m}$, as well as another slighter mode in the most mesophilic beech forests at lower elevation. The most well expressed mode can be connected to the coppice beech forests at middle elevation, also the mixed oak forests and pine plantations distributed at lower elevation, where the shrub layer is well developed with high species richness. Stem diameter class $5-10 \mathrm{~cm}$ shows its mode in the mesic (about and below $1100 \mathrm{~m}$ ) and submesic habitats at about $1300 \mathrm{~m}$ elevation. 
In the former case, it refers to the most mesic ravines along permanent or temporal springs in the mesophilic beech forests. The second mode is related to the coppice beech communities, distributed in the xeric places at middle elevation.

Table 6. Statistical parameters of the regression models. $* * * P<0.001$.

\begin{tabular}{lccc}
\hline Variable & Distribution & Model & Model significance $(\boldsymbol{F})$ \\
\hline \% stems 1-5 cm per 0.1ha & Asymmetric & GAM & $34.84^{* * *}$ \\
\% stems 5-10 cm per 0.1ha & Asymmetric & GAM & $57.21^{* * *}$ \\
\% stems 10-15 cm per 0.1ha & Complex & GAM & $55.66^{* * *}$ \\
\% stems 15-20 cm per 0.1 ha & Asymmetric & GAM & $41.20^{* * *}$ \\
\% stems 20-25 cm per 0.1ha & Asymmetric & GAM & $38.63^{* * *}$ \\
\% stems 25-30 cm per 0.1ha & Asymmetric & GAM & $19.45^{* * *}$ \\
\% stems 30-35 cm per 0.1ha & Asymmetric & GAM & $19.17^{* * *}$ \\
\% stems $>$ 35 cm per 0.1ha & Asymmetric & GAM & $9.43^{* * *}$ \\
Total stems per 0.1 ha & Asymmetric & GAM & $44.29^{* * *}$ \\
\hline
\end{tabular}

Each of the middle diameter classes has its specific manner of distribution in the abstract ecological space. For example, stem class 10-15 cm show complex surface form with several modes, centered in habitats with different conditions. These are the most mesic places at about $1200 \mathrm{~m}$ and the subxeric habitats at about $1300-1400 \mathrm{~m}$ elevation. Third mode can be found in the xeric habitats at about and below $1000 \mathrm{~m}$. The most numerous stems of 15-20 cm class appear in the subxeric and xeric habitats at lower elevation (about and below $1000 \mathrm{~m}$ ), where mixed oak forests and pine plantations dominate. The stems with diameters $20-25 \mathrm{~cm}$ prevail in the same habitats, but with the elevation increase, their numbers slowly decrease. This is happening most slowly in the mesic places and in the mesic beech forests their number almost remains constant in a very broad elevation belt (Figure 5).

Stems from thickest classes $(25-35 \mathrm{~cm})$ also show peculiar manner of distribution. For example, stems with diameters $25-30 \mathrm{~cm}$ have highest density in the submesic habitats at about $1400 \mathrm{~m}$. Second mode appears in the most xeric places at about and below $1000 \mathrm{~m}$. The next group $(30-35 \mathrm{~cm})$ has more obscure distribution. As a whole, the trend from previous stem class is repeated, but the stem density here is greatest at the lowest places (about $1000 \mathrm{~m}$ ) at various habitat moisture conditions. Another slight mode can be found in the most mesic places at about 1400-1500 m. The distribution of the thickest stems $(>35 \mathrm{~cm})$ is slightly different. Here can be outlined a well formed mode, centered in the mesic places at about 1400-1500 m elevation. It is obvious that thickest stem distribution is similar to the thinnest stem distribution, which is probably an indication of the "climax" state of these forests and the beginning of regeneration processes. These forests still remain preserved as isolated spots of old beech forests, which should be given special attention in the conservation policies of the management authorities.

The analysis of the total stem distribution shows that the forests with maximum stem number are distributed in the subxeric places on convex slopes at about 1000-1100 m elevation. Second maximum appears in the mesic habitats on steep slopes at elevation about and lower than $1000 \mathrm{~m}$. The first case refers to the coppice beech communities in the xeric places. The second one concerns the beech forests localized at the mesic slope bases along moist ravines. With the increasing elevation stem numbers abruptly falls. 
The same tendency applies when moving away from the centers of maximal stem number towards the low elevation, but the decrease here is much smoother.

\section{Discussion}

\section{Gradient relationships}

Numerous studies confirm the importance of habitat moisture condition (Whittaker 1960; Whittaker 1965; Whittaker \& Niering 1975; Peet \& Loucks 1977; Peet 1981; Allen et al. 1991), elevation (Whittaker 1965; Peet 1978; Peet 1981; Allen et al. 1991), geographic gradient, influencing the climate of territories (Whittaker 1960), potential solar radiation (Allen et al. 1991), soil chemical composition (Peet \& Christensen 1978; Christensen \& Peet 1984; Peet \& Christensen 1988), soil physical structure (Peet \& Loucks 1977), the bedrock type (Whittaker 1960), successional gradient (Peet \& Loucks 1977), and geographic latitudinal position (Peet 1978) for the vegetation structure and composition. The importance of habitat moisture and elevation is confirmed in this study too. Since the scale of our study is rather local, i.e. do not embraces territories with different climate regime, we cannot support or reject the importance of climatic gradient. The same is true for the bedrock type or soil composition because we did not used these variables in the current investigation.

The compensating effect against the moisture gradient, where the mesophilic vegetation types, ascending at greater elevation, are frequently found at more xeric conditions and vice versa, has been recognized Whittaker (1960). However, slope topography and elevation are not direct environmental gradient, but rather, a surrogate for complex interlocking environmental variables, which determine plant distribution (Whittaker 1956, 1960; Austin et al.1984; Austin 1985). If a particular biological meaning of the explained data variation is demanded, more appropriate would be a greater number of direct environmental gradients to be used in the gradient analyses (Austin 1985; Austin 2005). Unfortunately, measurement of direct environmental gradient is expensive and laborious task. On the other hand, indirect variables are easy, fast and cheap to be obtained.

On a regional scale, other studies (Bergmeier \& Dimopoulos 2001; Tsiripidis et al. 2007a), similar to the current one, which we can juxtapose to ours, have been done. The DCA ordination of Bergmeier \& Dimopoulos (2001) describes the moisture gradient effect on the mesic and relatively xeric habitats in Greece, which also applies to the subalpine and semi mountainous habitats. Significant correlations between the two DCA axes and the elevation have been found and interpreted as the gradients of temperature and rainfall. The significant correlation between the elevation and xeric habitat condition in our study can be explained with the presence of rain shadow on the south slope of Vitosha Mountain. Thus, this phenomenon leads to more xeric conditions across the subalpine habitats at about 1500-1600 m during the summer, especially over the south and southwest slopes, which inevitably influences vegetation structure and composition. Despite the scale difference in the two studies, their results confirm the primary importance of the elevation and habitat moisture for the forest and subalpine vegetation.

The environmental gradients are recognized as primary determinants for beech forest differentiation in Northern Greece (Tsiripidis et al. 2007). The elevation is qualified as the most important environmental gradient as well as the soil mineral content (Tsiripidis et al. 2007). With the secondary importance was the substrate type, which was in a 
direct dependence of the elevation and soil nutrient composition. It predetermines the physical texture and the chemical characteristics (calcium concentration and $\mathrm{pH}$ ) of the soil. These speculations cannot be confirmed or rejected in our study because such soil parameters were not analyzed here. The fine differentiation within the different ecological groups were ascribed to the microclimate and soil quality of the habitat (Tsiripidis et al. 2007), dependent on the exposition, relief and slope inclination, which were also confirmed in the current study.

Despite the primary importance of the complex environmental gradients, profound influences also have the natural disturbances such as forest fires (Whittaker 1960), landslides, windthrows, biotic disturbances etc. (White 1979), as well as the anthropogenic disturbance gradients like livestock grazing (Naveh \& Whittaker 1979), logging and others, which can influence to greater extent the vegetation composition and structure. However, frequent fires with low intensity in the past could only decrease stand density without causing substantial changes in their characteristics (Whittaker 1960).

\section{Vegetation cover and plant life forms}

Studying vegetation of Santa Catalina Mountains, Whittaker and Niering (1975) claimed for the presence of some trends, which we also try to verify in the current study. According to the authors, there was no correlation between the species number and productivity within the tree layer. This statement is clearly supported by our results, since the beech forests, where the canopy closure is highest, had lowest species richness, often presented only by the common beech itself. The second claim was, that the productivity and the diversity of perennial herbs should have bimodal distribution and relaxed competition. We obtained Gaussian distribution of herb cover, but our regressions incorporate four indirect gradients - not only one, as was the case in Whittaker and Niering (1975). However, we found strong correlation between the herb cover and diversity (Table 3). It is also stated that therophytes are concentrated in the open xeric habitats with increasing diversity and productivity from forests towards the open communities, which is supported by our results too (Figure 3; Figure 4).

Positive relationship between habitat moisture and vegetation cover (Whittaker 1956), dry/live leaf mass (Whittaker 1966), and productivity (Whittaker and Niering 1975) of tree layer have been found in other studies. Decrease of productivity and aboveground biomass of the mature "climax" forests with the advance towards the xeric places and higher elevation has also been found (Whittaker 1966), as well as positive correlation between the xeric gradient and shrub cover (Whittaker 1956), and productivity (Whittaker 1966; Whittaker \& Niering 1975). According to Whittaker (1956), along the moisture gradient shrub cover increases conversely to herb cover, i.e. they show negative relationship. Negative relationship has also been found between tree and shrub cover in forest communities (Whittaker, 1956; Whittaker and Woodwell, 1969). We have found similar trend along the elevation gradient. Herb cover increased and the shrub cover had complex relationship with the elevation (Figure 3; Table 3).

Despite that the herb productivity distribution along moisture gradient had bimodal form (Whittaker and Niering 1975) - with two maxima, first one in the subxeric habitats, and second one in the mesic ones - the results confirm its positive relationship with the more xeric habitats. Whittaker (1966) reported similar results, where productivity of herb layer was maximal in the marginal (extreme) moisture gradients 
parts, but the herb biomass increased along the elevation and reached its maximum in the mountainous fir forests.

Shrub productivity and diversity were weakly correlated when all species were taken together, not separated by plant life forms. Within the shrub layer, the different life forms had different centers of productivity and diversity (Whittaker and Niering 1975). However, we obtained strong positive correlation between shrub cover and diversity of phanerophytes, thereby rejecting the first hypothesis. Probable reason for this discrepancy can be found in the fact that we use as a surrogate for productivity the vegetation layer cover, which for the shrubs is higher in the poorer and dryer places as well as in the open subalpine habitats, where the species diversity is higher too. The second claim is supported by our results because it is obvious that phanerophytes and chamaephytes have different diversity centers (Figure 4).

In the primary vegetation layer there was no correlation between the diversity and productivity in habitats where the corresponding life form dominates (Whittaker and Niering 1975). This hypothesis is entirely supported since we have not found significant correlations between the cover of primary vegetation layer with species diversity of the dominant life form in neither of the analyzed plant communities.

In the temperate climate zone, the tree layer as a whole is poorer on species than the shrub or herb layers. The herb and shrub layers are at average poorer on species in highly closed forests than in more open forests and the herb communities (Whittaker and Niering 1975). Both statements are confirmed by us. According to Whittaker (1953), structural-functional character of the vegetation is determined by the relationship between plant life forms and their partial or complete turnover along the environmental gradient change. We have found obvious trend in the species turnover of some life forms and absence of tendency in others. For example, Figure 4 and Table 3 show that phanerophyte and chamaephyte distribution changes considerably with elevation change. Decreasing of phanerophytes and increasing of chamaephytes and hemicryptophytes with elevation increase have been found by Whittaker (1960), and Whittaker and Niering (1965) too. Chamaephytes seem to be influenced by the moisture gradient too, since species number in submesic subalpine habitats was higher. The relative continuity in the change of broadleaf forests (mainly common beech forests, Fagus sylvatica) into coniferous ones (mainly pine plantations, Pinus sylvestris and Pinus nigra), likewise the situation on the south slope of Vitosha Mountain, might not be always evident. Abrupt transition between community types can be seen most often when one or few tree species dominate in the forest vegetation (Whittaker 1956). In our case, abrupt change can only be observed in the transition between forests and open grasslands in the forest belt or between forests and subalpine meadows and pastures at higher elevation. Most probable reason for this phenomenon are the natural fires, human caused disturbances (fires, livestock grazing, mowing, agriculture) or abrupt change in environmental conditions of the habitat (Whittaker 1956).

Hemicryptophytes have not showed clear tendency, but as a whole, they were more numerous in the open subxeric subalpine habitats, as well as at lower elevation in variable moisture conditions. Probable limiting factor for their distribution is the dominant tree species competition since their numbers are significantly lower in the highly closed beech forests. According to Whittaker (1956), the contrast between different plant life form dominance, for example, between pastures and forests, can be explained in terms of the environmental conditions, giving advantage of one life form, which in its turn prevents the establishment of individuals from other life forms. Due to 
this phenomenon, both dominant life forms can sometimes replace each other abruptly instead of forming continuum along the environmental gradients.

Cryptophytes are most numerous in the beech forests and with the increasing elevation and xerophytisation of habitats they become less important. This can be explained with the ephemeral life cycle of most cryptophytes, which they complete before the emergence of tree leafs in the spring.

Therophytes reach its maximum in the most elevated and most xeric habitats, as well as in the lowland, highly influenced by human activity, territories. It is not surprising, given their ability to survive during extremely unfavorable periods, resulting from natural or anthropogenic factors. Positive relationship between therophyte richness and elevation has also been found by Whittaker (1960), which was explained with the relatively drier climate in the studied territory. However, negative relationships were also reported (Whittaker \& Niering 1968). In our case, we confirm the results of the former study, because, as already mentioned, during the summer months, rain "shadow" on the south and southwest slopes causes extreme drought, which inevitably induces species compositional changes in favor of therophyte number and decreasing of phanerophyte and cryptophyte numbers.

\section{Scale}

Studying understory vegetation of North Carolina at different scales, Reed et al. (1993) attributed correlation decrease with the decreasing scale of measurement to the interaction between the plant individuals, which mitigated the influence of environment at the smaller scales, where plant individuals compete directly for the same resources. This is mainly applicable to the open herb communities, but unfeasible to forest vegetation, where the competition between the individuals cannot be easily proved. The weaker correlation between the environment and vegetation at the smaller scales is due probably to unavoidable error in sampling. In other words, in the smaller sampling plots are found smaller number of plants, influenced to greater extent by chance (Reed et al. 1993). This contributes to the greater heterogeneity in the database and weaker correlations. For example, the total inertia in the DCA analysis at the $1 \mathrm{~m}^{2}$ scale is much greater, hence the explained variation in the data is lesser (Table 1).

Numerous previous studies assumed that the environmental gradients, correlated most strongly with species composition would have to be similar at the different scales of measurement (Reed et al. 1993). We have confirmed this hypothesis, but this, however, does not mean that the vegetation pattern at the smaller scale is a miniature version of that on the coarser scales. Consequently, extrapolation between the different scales should be avoided at any cost (Palmer, 1990).

In contrast to Reed et al. (1993), we confirmed the hypothesis that with the increase of sampling area, covered by the sampling plots, the correlation between the environment and vegetation variables also increases. According to the authors, the reason for the weaker correlation found in their study was the data heterogeneity and the large number of interacting variables when sampling extensive territories. Like Wiser et al. (1996), however, we maintain that, despite the great variation in vegetation composition, the continuity of indirect gradient importance is confirmed at both scales as well as across different scales.

In conclusion, it can be summarized, that the predictive power of the indirect gradients is valid for the habitat scale $(0.1 \mathrm{ha})$, as well as at the microhabitat scale $\left(1 \mathrm{~m}^{2}\right)$. Nevertheless, for future environmental gradient-vegetation studies it should be 
kept in mind that the use of different sampling scales is of crucial importance for the correct understanding of the vegetation pattern and processes (Reed et al. 1993).

\section{Stand structure}

Positive relationship between xeric gradient and the total stem number have been previously reported (Whittaker 1956), where along the xeric environmental gradient stand height decreased. According to the author, the increasing stem number expresses the stand low stature and higher density, where the numerous thin stems in the xeric habitats belong to species with low habitus. However, in our case, it refers to the management practices of the beech forests. The higher stem number is the outcome from the coppice nature of the beech forests in these habitats, rather than high species number. Detected tendency in Whittaker (1956), at some extent, applies to the oak forests and pine plantations in the area, where, indeed, the greater stem number is due to higher species richness.

Three general types of stand development have been suggested (Peet 1981). They were considered as three referent points in the cenocline continuum varying accordingly to the elevation and habitat moisture, which are applicable to the analyzed by us stands. In the favorable sites at middle elevation, tree species establish immediately after the disturbance event. This is followed by rapid growth, canopy closure and competitive displacement of the undergrowth. This results in bell-shaped diameter distributional curves. Meanwhile, the diversity and productivity decrease, while the biomass remains constant (Peet 1981). After decades or centuries of stagnation, following large tree collapse, the forest canopy eventually opens, allowing regeneration to be restarted. During this period, the biomass, diversity and productivity undergo dramatic changes, responding to the forest structural reorganization. This dynamic model is applicable to the Fagus-Hepatica, Fagus-Galium, Fagus-Luzula and Fagus-Festuca type communities in the studied area. The regeneration in these forests is periodical and expresses the variability of seedling germination in the favorable for growth places. The competition between tree species in these places is relatively unimportant and the diameter distribution shows irregular peaks, resulting from periodic regeneration.

At high or middle elevation, in the xeric and poor habitats, seedling establishment after disturbances is unusually slow (Peet 1981). These habitats on the south slope of Vitosha are dominated by Pinus-Fragaria, Fagus-Corylus-Brachypodium, QuercusCornus and Pinus-Crataegus communities. The forests in such places slowly reach the biomass, diversity and productivity from the period before the disturbance, while the regeneration rate is constant. It is typical for the beech forests in the area, where the regeneration is exceptionally of sprouting origin and seedling regeneration is almost lacking. Similar situation is found in the pine plantations of Pinus sylvestris and Pinus nigra in the xeric habitats at middle and low elevation, where seedling regeneration is also lacking. The common beech there can be found in multiply separated sprouting spots, where canopy openings allow undergrowth to occur.

Acknowledgements. The author is grateful to Dragomir Zahariev and Eli Pavlova for their indispensable help on the field. This study was partly funded by University of Forestry's (Sofia) Scientific Fund grant No 47/1304, 2009. 


\section{REFERENCES}

[1] Allen, R., Peet, R. \& Baker, W. (1991): Gradient analysis of latitudinal variation in Southern Rocky Mountain forest.- Journal of Biogeography 18: 123-139.

[2] Austin MP, Heyligers PC. (1991): New approach to vegetation survey design: gradsect sampling. In: Margules C.R. and Austin M.P. (eds) Nature Conservation: Cost Effective Biological Surveys and Data Analysis, CSIRO, Canberra, Australia, pp. 31-36.

[3] Austin, M. \& Smith, T. (1989): Anew model for the continuum concept. -Vegetatio 83: 350-47.

[4] Austin, M. (1985): Continuum concept, ordination methods, and niche theory. -Annual Review of Ecology and Systematics 16: 39-61.

[5] Austin, M. (2005): Vegetation and environment: discontinuities and continuities. In: Van der Maarel, E (ed.), Vegetation ecology, pp. 52-84, Blackwell Publishing.

[6] Austin, M., Cunningham, R. \& Fleming, P. (1984): New approaches to direct gradient analysis using environmental scalars and statistical curve-fitting procedures. -Vegetatio 55: 11-27.

[7] Bergmeier, E. \& Dimopoulos, P. (2001): Fagus sylvatica forest vegetation in Greece: Syntaxonomy and gradient analysis. -Journal of Vegetation Science 12: 109-126.

[8] Christensen, L. \& Peet, R. (1984): Convergence during secondary forest succession. Journal of Ecology 72: 25-36.

[9] Dyakov, N. \& Zhelev, P. (2013): Alien species invasion and diversity of riparian forest according to environmental gradients and disturbance regime. -Applied Ecology and Environmental Research 11: 249-272.

[10] Dyakov, N. (2012): Classification of forest vegetation on the south slope of Vitosha Mountain, Western Bulgaria.- Forestry Ideas 43: 57-77.

[11] Dyakov, N. (2013): Successional Pattern, Stand Structure and Regeneration of Forest Vegetation According to Local Environmental Gradients.- Ecologia Balkanica, Vol. 5, Issue 1, pp. 69-85.

[12] Hill, M. (1979): TWINSPAN - A FORTRAN program for arranging multivariate data in an ordered two-way table by classification of individuals and attributes. Cornell University Ithaca, N Y., 90 pp.

[13] Jongman R, ter Braak C, van Tongeren O. (2004): Data Analysis in Community and Landscape Ecology. Cambridge University Press.

[14] Naveh, Z. \& R. Whittaker. (1979): Structural and floristic diversity of shrublands and woodlands in northern, Israel and other Mediterranean areas. Vegetatio 41: 171-190.

[15] Palmer M. (1993): Putting things in even better order: the advantages of canonical correspondence analysis. -Ecology 84: 2215-2230.

[16] Palmer, M. W. (1990): Spatial scale and patterns of species-environment relationships in hardwood forests of the North Carolina piedmont. Coenoses 5: 79-87.

[17] Peet, R. \& Christensen, L. (1978): Hardwood Forest Vegetation of North Carolina Piedmont. Proceedings of the 16-th IPE.

[18] Peet, R. \& Christensen, L. (1988): Changes in species diversity during secondary forest succession on the North Carolina Piedmont. In: During, H.I., M.I.A. Werge \& J.H. Willems (eds.), Diversify and pattern in plant communities. pp. 233-245. SPB Academic Publishing, The Hague, The Netherlands.

[19] Peet, R. \& Loucks, O. (1977): A gradient analysis of Southern Wisconsin Forests. Ecology 58: 485-499.

[20] Peet, R. (1978): Latitudinal variation in southern Rocky Mountain forests. -Journal of Biogeography 5: 275-89.

[21] Peet, R. (1981): Forest vegetation of Colorado Front Range.- Vegetatio 45: 3-75.

[22] Reed, R., Peet, R., Palmer, M. \& White, P. (1993): Scale dependence of vegetationenvironment correlations: A case study of a North Carolina piedmont woodland. -Journal of Vegetation Science 4: 329-340. 
[23] Šmilauer, P. (1999-2003): CanoDraw for Windows, version 4.1. Glenn Randers-Pehrson.

[24] Spearman, C. (1904): The proof and measurement of association between two things. American Journal of Psychology 15: 72-101.

[25] StatSoft, Inc. (2007): STATISTICA (data analysis software system), version 8.0. www.statsoft.com.

[26] ter Braak C. (1986): Canonical correspondence analysis: a new eigenvector technique for multivariate direct gradient analysis.- Ecology 67: 1167-1179.

[27] ter Braak, C., \& P. Šmilauer. (1998): CANOCO reference manual and User's guide to Canoco for Windows: Software for Canonical Community Ordination (version 4). Microcomputer Power, Ithaca.

[28] Thomas, Y. \& Mitchell, N. (1991): Generalized additive models in plant ecology.Journal of Vegetation Science 2: 587-602.

[29] Tsiripidis, I., Vassiliki, K., Alifragis, D. \& Athanasiadis, N. (2007): Classification and gradient analysis of the beech forest vegetation of the southern Rodopi (Northeast Greece). -Folia Geobotanica 42: 249-270.

[30] White, P. (1979): Pattern, process, and natural disturbance in vegetation.- Botanical Review 45: 229-299.

[31] Whittaker, R. \& G. Woodwell. (1969): Structure, production, and diversity of the oakpine forest at Brookhaven, New York. -Journal of Ecology 57: 155-174.

[32] Whittaker, R. \& Niering A. (1975): Vegetation of the Santa Catalina Mountains, Arizona. V. Biomass, production, and diversity along the elevation gradient. -Ecology 56: 771790.

[33] Whittaker, R. \& Niering, A. (1968): Vegetation of the Santa Catalina Mountains, Arizona: Limestone and Acid Soils. -The Journal of Ecology 56: 523-544.

[34] Whittaker, R. (1953): A considering of climax theory: the climax as a population and pattern. -Ecological Monographs 23: 41-78.

[35] Whittaker, R. (1956): Vegetation of the Great Smoky Mountains. -Ecological Monographs 26: 1-80.

[36] Whittaker, R. (1960): Vegetation of the Siskiyou Mountains, Oregon and California. Ecological Monographs 30: 279-338.

[37] Whittaker, R. (1965): Dominance and diversity in land plant communities. -Science 147: 250-260.

[38] Whittaker, R. (1966): Forest dimensions and production in the Great Smoky Mountains. Ecology 47: 103-121.

[39] Whittaker, R. (1978): Direct gradient analysis. In: Whittaker, R. (ed.) Classification of Plant Communities. Junk, The Hague, 408 pp.

[40] Wiser, S., Peet, R. \& White, P. (1996): High-elevation rock outcrop vegetation of the Southern Appalachian Mountains.- Journal of Vegetation Science 7: 703-722. 